\title{
An Otherwise Typical Case of Non-Japanese Hairy Cell Leukemia With CD10 and CDw75 Expression: Response to Cladaribine Phosphate Therapy Cherie H. Dunphy, ${ }^{1 *}$ Yagnesh V. Oza, ${ }^{2}$ and Milton E. Skelly ${ }^{3}$ \\ ${ }^{1}$ Division of Hematopathology, Department of Pathology, St. Louis University Health Sciences Center, St. Louis, Missouri \\ ${ }^{2}$ Department of Internal Medicine, Good Samaritan Regional Health Center, Mount Vernon, Illinois \\ ${ }^{3}$ Department of Pathology, Good Samaritan Regional Health Center, Mount Vernon, Illinois
}

\begin{tabular}{lll}
\hline \hline $\begin{array}{r}\text { Hairy cell leukemia (HCL) in Western pa- } \\
\text { tients typically expresses CD19, CD20, }\end{array}$ & $\begin{array}{l}\text { presented typically with pancytopenia; how- } \\
\text { ever, the immunophenotype was atypical }\end{array}$ \\
CD11c, CD25, HLA-DR, and IgG/lambda & with expression of CD10 and CDw75. \\
and lacks expression of CD5 and CD10. The & CDw75 expression has not previously been \\
immunophenotype is in contrast to Japa- & described in either Japanese or non-Japa- \\
nese HCL which typically expresses CD5 & nese HCL. The patient achieved a marked \\
and CD10. Western and Japanese HCL also & partial pathologic response and complete \\
differ in their clinical presentation and re- & clinical response to treatment with cladari- \\
sponse to treatment with $\alpha$-interferon. We & bine phosphate. J. Clin. Lab. Anal. 13:141- \\
report a case of non-Japanese HCL which & $\begin{array}{lll}\text { 144, 1999. } & \text { o 1999 Wiley-Liss, Inc. }\end{array}$
\end{tabular}

Key words: hairy cell leukemia; CD10; CDw75; cladaribine phosphate therapy

\section{INTRODUCTION}

Hairy cell leukemia (HCL) is a chronic B-lineage leukemia which typically presents in Western patients with pancytopenia/splenomegaly and the following immunophenotype: CD19+, CD20+, CD11c+, CD25+, HLA-DR+, CD5-, CD10with selective expression of IgG/lambda. Monoclonal kappasurface expression may also occur. The tartrate-resistant acid phosphatase (TRAcP) reaction is positive in $98 \%$ of Western cases $(1,2)$. Clinical trials in Western HCL have shown an $80 \%$ response rate ( $10 \%$ complete remissions) to $\alpha$-interferon $(\alpha$-IFN) and a $90 \%$ response rate $(65 \%$ complete remissions) to 2-deoxycoformycin (pentostatin) (3). HCL in Japanese patients typically presents with marked leukocytosis and often expresses CD10 and CD5 (4). The TRAcP is generally much weaker and, in this context, 50\% of Japanese HCL cases are positive $(4,5)$. The response rate of Japanese HCL to $\alpha$-IFN therapy is much less (43\%) (6). The comparative response rates of Japanese and non-Japanese HCL to cladaribine phosphase (2-CDA) have not been reported.

We present a case of non-Japanese HCL, typically presenting with pancytopenia, which showed the typical immunophenotype of Western HCL except for the coexpression of CD10 and CDw75. The patient was treated with 2-CDA and achieved a marked partial pathologic response and complete clinical response. We present our case and describe our findings.

\section{CASE REPORT}

A 53-year-old white man presented with a one-week history of fever, severe aches and pains, and a cough productive of whitish sputum. Physical examination revealed no lymphadenopathy and mild tenderness on palpation of the left upper abdominal quadrant. The spleen was not palpable. Complete blood count (CBC) upon presentation revealed a white blood cell count (WBC) of 2,300/ $\mu \mathrm{L}$ (60\% segmented neutrophils, $4 \%$ band forms, and 33\% lymphocytes), a hemoglobin $(\mathrm{Hgb})$ of $8.5 \mathrm{~g} / \mathrm{dL}$, and a platelet count of $73,000 / \mu \mathrm{L}$. Chest $\mathrm{X}$-ray revealed an inferior lingular pneumonia. Computerized axial tomographic (CT) scans of the abdomen and pelvis revealed normal liver and spleen and no evidence of retroperitoneal or pelvic lymphadenopathy. A bone marrow aspiration and core biopsy were performed and submitted for morphology as well as flow cytometric immunophenotyping (FCI). A diagnosis of HCL (90\% of marrow cellularity) was rendered. He received cladaribine phosphate (2-CDA) (8.5 $\mathrm{mg}$, daily continuous infusion over 24 hours for seven days). A bone marrow biopsy performed 11 weeks after completion

*Correspondence to: Dr. Cherie Dunphy, Department of Pathology, St. Louis University School of Medicine, 1402 S. Grand, St. Louis, Missouri 63014. E-mail: dunphyc@SLUCarel.SLUH.edu

Received 17 November 1998; Accepted 5 February 1999 


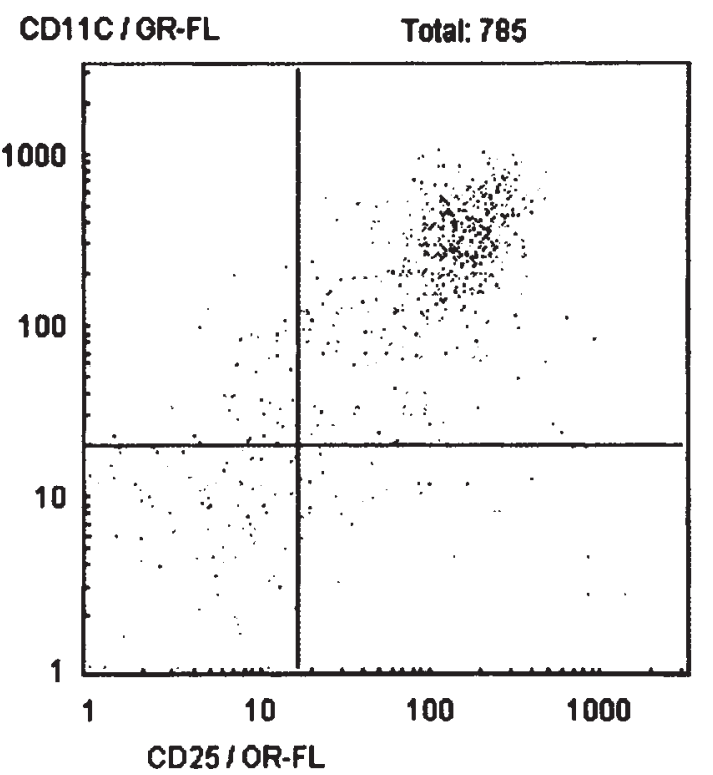

Fig. 1. Flow cytogram of cells showing dual expression of CD11c and CD25 in upper right box.

of the chemotherapy revealed $25 \%$ of the marrow cellularity composed of residual HCL. At last follow up, six months after cessation of chemotherapy, his CBC showed normalization (WBC, 3,200/ $\mu \mathrm{L} ; \mathrm{Hgb}, 13.8 \mathrm{~g} / \mathrm{dL}$; and platelet count, $126,000 / \mu \mathrm{L})$.

\section{MATERIALS AND METHODS \\ Cytomorphology/Flow Cytometry}

A Wright's-stained smear was prepared from the flow cytometry specimen of the bone marrow aspirate. The remainder of this specimen was analyzed for various antigens on an Ortho Cytoronabsolute flow cytometer (Ortho Diagnostic Systems, Raritan, NJ) using standard techniques and the following commercially-available monoclonal antibodies: CD3, CD4, and CD45 (Becton-Dickinson, San Jose, CA); CD5 and CD8 (Gen Trak, Inc., Wayne, PA); CD10, CD11c, CD14 (MY4), CD19, CD20, and CD56 (Coulter Clone, Coulter Immunology, Hialeah, FL); CD25 (DAKO, Carpinteria, CA); HLA-DR (Ortho Diagnostic Systems); and IgA, IgD, IgG, IgM, kappa and lambda (Kallestad, Inc., Chaska, MN).

\section{Histology/lmmunohistochemistry}

The hematoxylin-eosin (HE) stained sections of the bone marrow core biopsy from the referring institution were reviewed. The following immunoperoxidase stains were performed on the received paraffin-embedded tissue block of the core biopsy using the DAKO LSAB-2 peroxidase system: DBA.44 and bcl-2 (DAKO); TRAcP (Zymed Laboratories, San Francisco, CA); and LN-1 (CDw75; Novocastra Laboratories, UK).

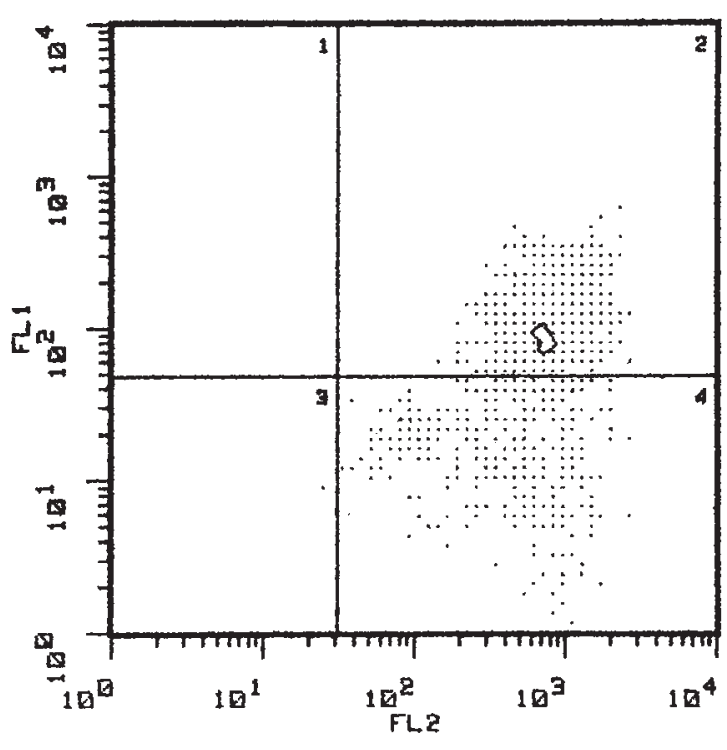

Fig. 2. Flow cytogram of cells showing dual expression of CD10 (FL1) and CD45 (FL2) in upper right box.

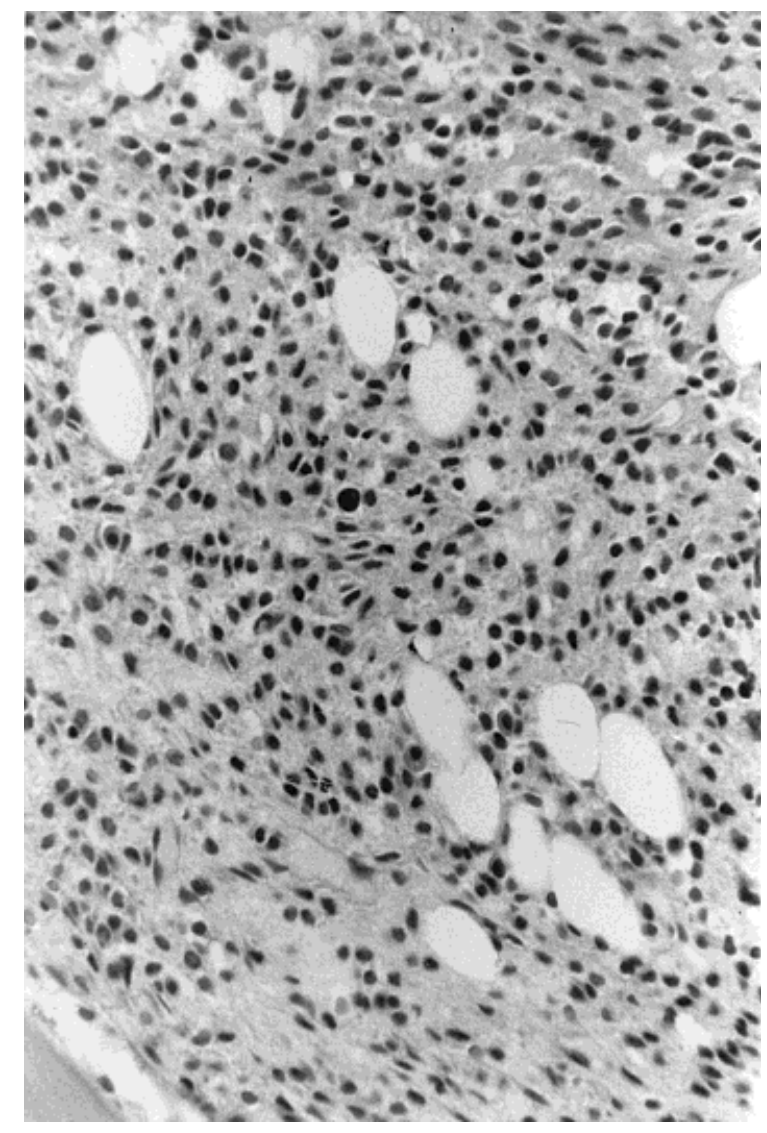

Fig. 3. Photomicrograph of bone marrow core biopsy section showing hypercellularity of marrow composed of lymphoid cells in a background of marked fibrosis (Hematoxylin-eosin stain, $\times 400$ ). 


\section{RESULTS}

\section{Cytomorphology/Flow Cytometry}

Flow cytometric analysis of the bone marrow revealed a hypocellular specimen $(4,100 / \mu \mathrm{L})$ with $37 \%$ of cells within the lymphocyte region, $25 \%$ within the monocyte region, and $38 \%$ within the granulocyte region. Cells within the lymphocyte region were composed of $66 \% \mathrm{~T}$ cells $(\mathrm{CD} 4 / \mathrm{CD} 8$ ratio is 1.5 ) and $17 \%$ monoclonal B cells with expression of CD19, CD20, HLA-DR, CD10, CD11c, and CD25 as well as IgG, Kappa (Figs. 1 and 2). There was no coexpression of CD5 by the monoclonal B-cell population. Cells within the monocyte region were composed of $76 \%$ of cells with the same monoclonal B-cell immunophenotype. Cytomorphological examination of the smear prepared from the flow cytometry specimen confirmed the hypocellularity by flow cytometric analysis and the absence of spicules. Lymphoid cells of varying sizes were present with occasional monocytoid appearance. Occasional cells had fine hairy projections. The flow cytometric data combined with cytomorphology was diagnostic of the flow cytometry specimen of the bone marrow

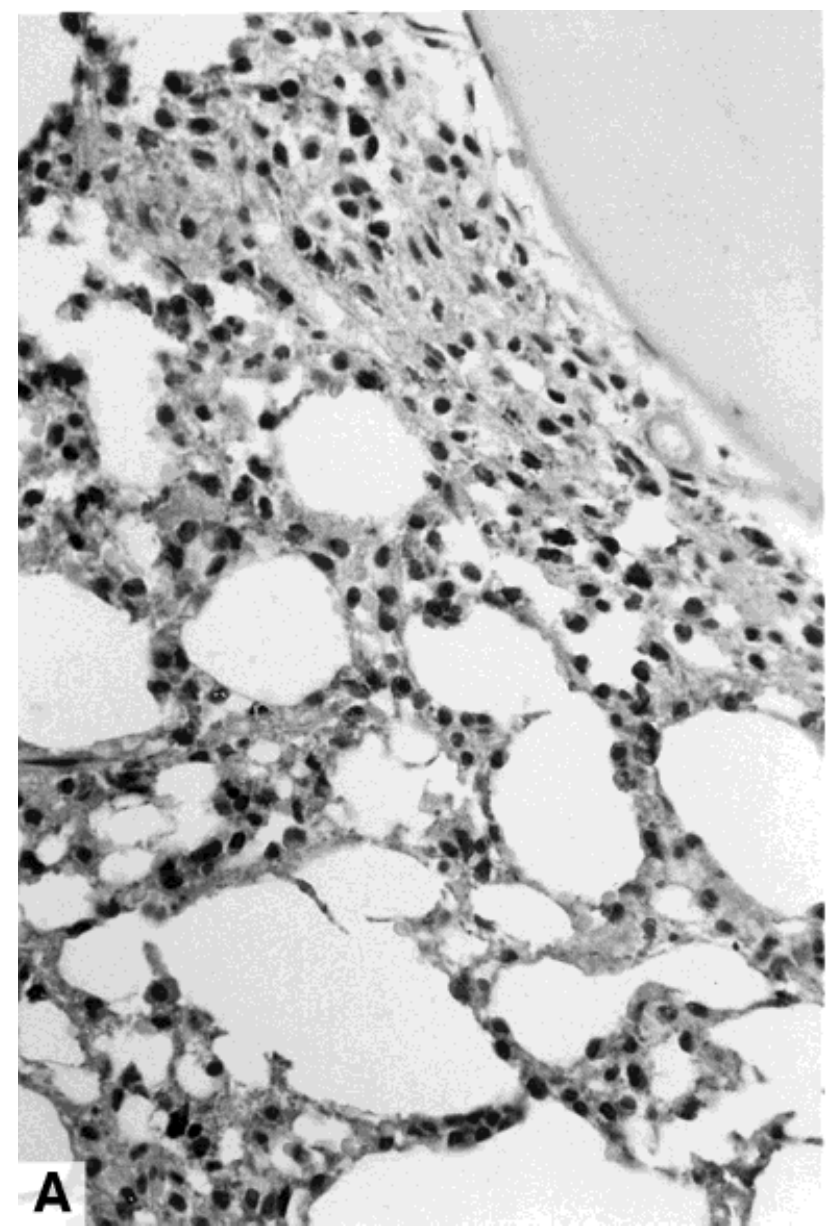

by hairy cell leukemia, representing $25 \%$ of cells within the flow cytometry specimen.

\section{Histology/Immunohistochemistry}

Review of HE-stained sections of the bone marrow core biopsy revealed a markedly hypercellular marrow (90\% cellularity) with approximately $90 \%$ of the marrow cellularity composed of lymphoid cells in a background of marked fibrosis (Fig. 3). The cells were clearly separated from each other and were immunoreactive with DBA.44, TRAcP, and LN-1 and nonimmunoreactive with bcl-2 (Fig. 4).

\section{DISCUSSION}

Hairy cell leukemia in Japanese and non-Japanese patients is characterized by different clinical presentations, immunophenotypic findings, and clinical responses to the same chemotherapeutic regiments. In the series of Katayama et al. (4), CD10 was expressed in $90 \%$ of Japanese cases whereas CD10 expression was observed in only $5 \%$ of nonJapanese cases from three series (7-9). There was no correla-

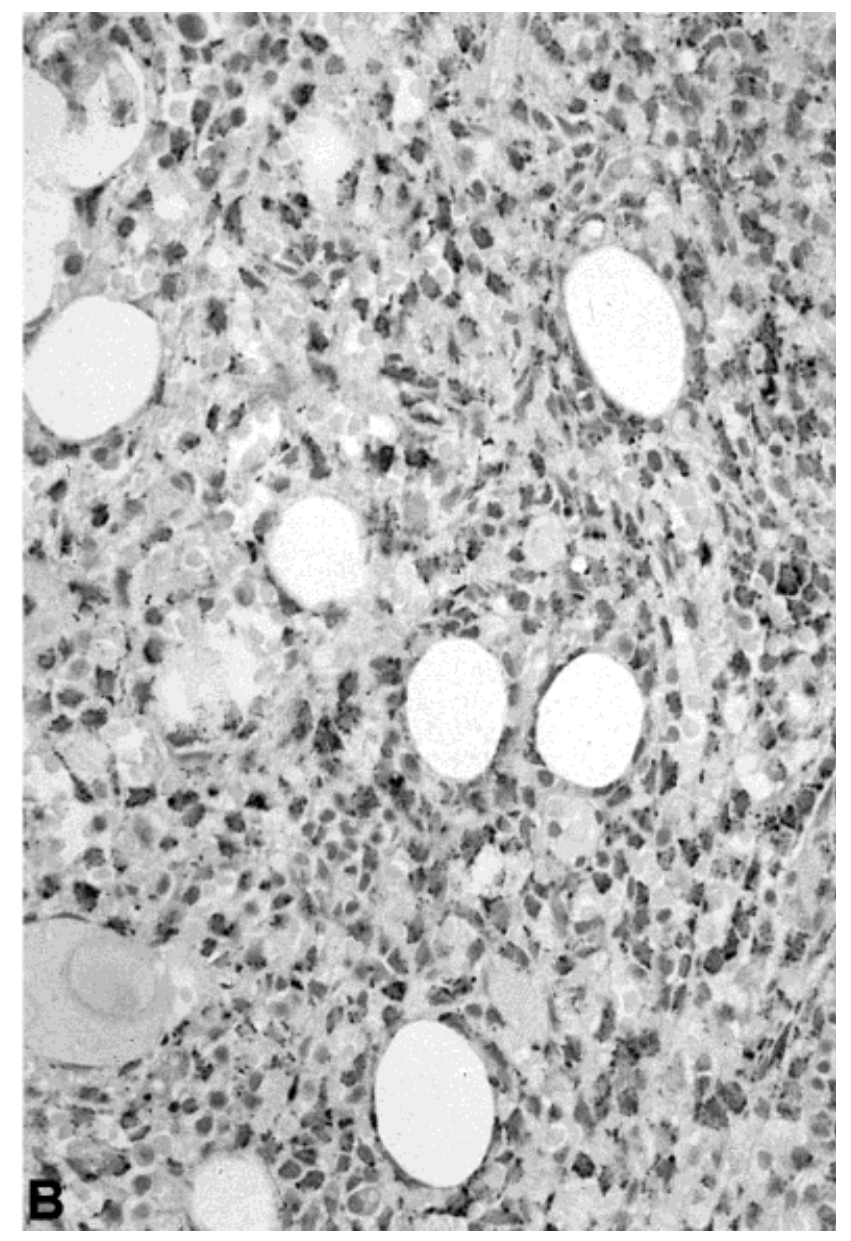

Fig. 4. Photomicrographs of immunoperoxidase stains of the bone marrow core biopsy showing immunoreactivity of the lymphoid cells with DBA.44 (A, $\times 400)$ and TRAcP $(\mathbf{B}, \times 400)$. 
tion of these CD10+ non-Japanese cases with clinical response to therapy. Foon suggested that the expression of CD10 in the Japanese cases be considered an aberration associated with a malignant transformation of mature Bcells (10).

We report a case of CD10+ HCL in a non-Japanese patient. The morphology and FCI were otherwise typical of HCL. In addition, DBA.44 and TRAcP intensely stained the cells. Of interest, LN-1 (CDw75) also intensely stained the cells. LN-1 reacts primarily with germinal center B-cells but may also be present in other types of B-cell lymphomas/leukemias (11). The expression of CDw75 has not been described in either Japanese or non-Japanese HCL. The clinical significance of this expression in our case is unclear. Our patient had a complete clinical response and marked partial pathologic response to 2-CDA therapy. Comparative responses of Japanese and non-Japanese HCL cases to 2-CDA has not been reported and would be an interesting study. In addition, this represents the first case reported of a CD10+ non-Japanese HCL with a documented clinical response to therapy. The clinical significance of CD10 and CDw75 positivity in otherwise typical Western HCL is uncertain and may be determined by accruing more cases. The availability of these immunophenotypic markers may define the clinical relevance of these markers in non-Japanese HCL.

\section{REFERENCES}

1. Variakojis D, Vardiman JW, Golomb HM. Cytochemistry of hairy cells. Cancer 1980;45:72-77.

2. Katayma I, Aiba M. Tartrate-resistant acid phosphatase reaction [letter]. Am J Clin Pathol 1980;73:143.

3. Cheson BD, Martin A. Clinical trials in hairy cell leukemia. Current status and future directions. Ann Intern Med 1987;106:871-878.

4. Katayama I, Hirashima K, Maruyama K, et al. Hairy cell leukemia in Japanese patients: a study with monoclonal antibodies. Leukemia 1987;1:301-305.

5. Katayama I, Mochino T, Honma T, Fukuda M. Hairy cell leukemia: a comparative study of Japanese and non-Japanese patients. Semin Oncol 1984;11(4):486-492.

6. Tominaga K, Sho S, Katayama I. $\alpha$-interferon therapy for Japanese patients with hairy cell leukemia. Leukemia 1988;2:554-555.

7. Tubbs RR, Savage RA, Sebek BA, Fishleder A, Weick JK. Antigenic phenotype of splenic hairy cells. Am J Med 1984;76:199-205.

8. Jansen J, Ottolander den GJ, Schuit HRE, Waayer JLM, Hijmans W. Hairy cell leukemia: its place along the chronic B cell leukemias. Semin Oncol 1984;11:386-393.

9. Falini B, Schwarting R, Erber W, et al. The differential diagnosis of hairy cell leukemia with a panel of monoclonal antibodies. Am J Clin Pathol 1985;83:289-300.

10. Jennings CD, Foon KA. Recent advances in flow cytometry: application to the diagnosis of hematologic malignancy. Blood 1997; 90(8):2863-2892.

11. Marder RJ, Variakojis D, Silver J, Epstein AL. Immunohistochemical analysis of human lymphomas with monoclonal antibodies to B cell and Ia antigens reactive in paraffin sections. Lab Invest 1985;52:497-504. 